\section{P0-0501 GLIBENCLAMIDE CLOSES NEONATAL DUCTUS ARTERIOSUS IN RATS}

K Momma, K Toyoshima, E Hayama, T Nakanishi. Pediatric CardiologyHeart Center, Tokyo Women's Medical University, Tokyo, Japan

\subsection{6/archdischild-2014-307384.1145}

Background Treatment for patent ductus arteriosus (PDA) in premature infants may fail following perinatal indomethacin exposure. Glibenclamide, a sulfonylurea, constricts the fetal rabbit ductus in vitro, and fetal rat ductus in vivo. Clinical doses for diabetes include $0.1 \mathrm{mg} / \mathrm{kg}$ (adults) and $1 \mathrm{mg} / \mathrm{kg}$ (children with neonatal diabetes).

Aims To show ductus constriction acceleration with Glibenclamide in newborn rats as a model of treatment for premature PDA.

Methods Glibenclamide (1 $\mathrm{mg} / \mathrm{Kg}$ ) was injected intraperitoneally (IP) to newborn Wistar rats immediately after cesarian section, and the ductus diameter was studied at $60 \mathrm{~min}$ with rapid whole-body freezing, by cutting on a freezing microtome, and measurements performed on a microscope using a micrometre. Two near-term rat models were studied on the 21 st day. In a chronic fetal indomethacin-exposure model, mother rats were treated with indomethacin (10 mg/kg, gavage) for two days before birth. In a hypoxia model, neonates were incubated in $8 \%$ oxygen. In a premature model, rats were delivered on the 19 th day (two days before term) and incubated in $80 \%$ oxygen. Results In these three models, neonatal ductus constricted slowly. Glibenclamide $1 \mathrm{mg} / \mathrm{kg}$, caused accelerated constriction and the effects were dose-dependent. Glibenclamide $(1 \mathrm{mg} / \mathrm{kg}, \mathrm{IP})$ was associated with hypoglycemia, which was controlled with $50 \%$ glucose via gavage.

Conclusions Glibenclamide (1 mg/kg, IP) constricts the neonatal ductus in $60 \mathrm{~min}$ in three rat models. Hypoglycemia was controlled with glucose, indicating its usefulness in the treatment of PDA in premature infants.

\section{PO-0502 CONGENITAL HEART DISEASE AT MATERNIDADE JÚLIO DINIS 2012-2013}

IJ Nascimento, ${ }^{1} \mathrm{~J}$ Correia, ${ }^{2}$ ANA Guedes, ${ }^{2} \mathrm{E}$ Proença, ${ }^{3} \mathrm{M}$ Loureiro, ${ }^{3} \mathrm{~S}$ Alvares. ${ }^{1}$ Paediatrics, Centro Hospitalar Porto, Porto, Portugal; ${ }^{2}$ Neonatal Intensive Care Unit, Centro Hospitalar Porto, Porto, Portugal; ${ }^{3}$ Paediatrics Cardiology, Centro Hospitalar Porto, Porto, Portugal

\subsection{6/archdischild-2014-307384.1146}

Background/aim Congenital heart disease (CHD) is the most common congenital disorder in newborns (prevalence ranges from 6 to 13 per 1000 live births). Transversal study of the newborns diagnosed with CHD at Maternidade Júlio Dinis between 2012-2013.

Methods Patients were identified by searching the hospital's electronic discharge records of the ICD-9 for each CHD (745.0747.11). The following data were analysed: gender;gestational age; birth weight;pregnancy and delivery type; need of resuscitation;family history and maternal conditions that increase the risk for CHD; echocardiography reason and source of referral; clinical manifestations; paediatric cardiology agreement on the diagnosis; treatment and follow-up.

Results A total of 161 patients were documented, corresponding $24,8 \%$ to preterm newborns. The prevalence of echocardiographic findings was 26,8 per 1000 live births. At birth, resuscitation was needed in $20,5 \%$ patients. Cardiovascular findings suggestive of CHD were the reason to request echocardiogram in $75,8 \%$ cases and prenatal suspicion was responsible for $19,9 \%$. Ventricular septal defect was the most prevalent $(53,4 \%)$ CHD. Complex heart defects were found in $6,8 \%$ patients. A total of 101 patients were referred to paediatric cardiology and the concordance in diagnosis was around 99\%. Surgical repair was performed in $5,6 \%$ patients. During this 2 years period, mortality related to $\mathrm{CHD}$ was 0,67 per 1000 infants $(<1$ year age).

Conclusion This portuguese CHD study shows a high prevalence of these disorders. Congenital heart defects are common conditions that have significant impact on morbidity, mortality and healthcare costs. A multidisciplinary team able to detect most of them in the neonatal period is crucial to minimise it.

\section{PO-0503 TEN YEAR STUDY OF PREVALENCE AND DIAGNOSIS OF CONGENITAL HEART DISEASE (CHD) IN AN ASIAN COUNTRY: IMPLICATIONS ON ANTENATAL DIAGNOSIS AND NEWBORN SCREENING}

${ }^{1}$ A Ngeow, ${ }^{1} \mathrm{MG}$ Tan, ${ }^{2}$ WC Tan, ${ }^{3} \mathrm{JTL}$ Choo, ${ }^{3} \mathrm{TH}$ Tan, ${ }^{1} \mathrm{DKL}$ Chan. ${ }^{1}$ Neonatal and Developmental Medicine, Singapore General Hospital, Singapore, Singapore; ${ }^{2}$ Obstetrics and Gynaecology, Singapore General Hospital, Singapore, Singapore, ${ }^{3}$ Cardiology Service Department of Paediatric Subspecialties, KK Women's and Children's Hospital, Singapore, Singapore

\subsection{6/archdischild-2014-307384.1147}

Rationale Congenital heart disease (CHD) constitutes a significant proportion of birth defects and is a leading cause of mortality. Current literature regarding the local prevalence of $\mathrm{CHD}$ and timeliness of diagnosis is not available.

Objective This study aims to determine the live birth prevalence of CHDs in Singapore General Hospital (SGH), the antenatal diagnosis rate, and the proportion of CHD patients diagnosed after discharge from the SGH neonatal unit.

Methods This was a retrospective observational study. All livebirths at SGH from January 2003 to December 2012 diagnosed with CHDs according to the hospital's birth defect register were

\section{Abstract PO-0503 Table 1 CHD prevalence}

\begin{tabular}{|c|c|c|c|}
\hline $\begin{array}{l}\text { BPA } \\
\text { Classification }\end{array}$ & Congenital heart defect & $\begin{array}{l}\text { Frequency } \\
(n=150)\end{array}$ & $\begin{array}{l}\text { Percentage of all } \mathrm{CHD} \\
(\%)\end{array}$ \\
\hline 745.10 & TEA & 1 & 0.7 \\
\hline 745.20 & TOF & 3 & 2.0 \\
\hline 745.40 & vsD & 82 & 54.7 \\
\hline 745.69 & AVSD & 3 & 2.0 \\
\hline 745.90 & Unspecified defect of septal closure & 1 & 0.7 \\
\hline 746.00 & Fulmonsry valve anomaly. urspecified & 2 & 1.3 \\
\hline 748.01 & Fulmonay atresis & 1 & 0.7 \\
\hline 746.02 & Pulmonary stenosis & 27 & 18 \\
\hline 748.09 & Other pulmonary valve defect & 1 & 0.7 \\
\hline 748.30 & Congenital stenosis of acticvalve & 1 & 0.7 \\
\hline 748.60 & Congeninal mitrel irsufficiency & 1 & 0.7 \\
\hline 748.70 & Hypoplas tic left heart & 1 & 0.7 \\
\hline 740.87 & Dextrocardia & 3 & 2.0 \\
\hline 748.90 & Unspecified anomaty of heart & 10 & 6.7 \\
\hline 747.10 & Cosrctation of sorts & 3 & 2.0 \\
\hline 747.21 & Anomalies of aortic ach & 1 & 0.7 \\
\hline 747.30 & Anomslies of pulmonary artery & 4 & 2.7 \\
\hline 747.41 & TAPVD & 2 & 1.3 \\
\hline 747.49 & Other anomalies of grest veirs & 1 & 0.7 \\
\hline 747.90 & Uns pecified enomaly of circulatory system & 2 & 1.3 \\
\hline
\end{tabular}

